\title{
CASOLBA: BALLOON CALIBRATION OF SOLAR CELLS
}

\author{
Etienne Rapp $^{(1)}$, Valérie Pichetto $^{(1)}$, Christian Elisabelar $^{(1)}$, Carsten Baur $^{(2)}$, Denis Bausch $^{(1)}$, Maxime Jeunet ${ }^{(1)}$ \\ (1) CNES, 18 avenue Edouard Belin 31401 Toulouse Cedex 9, France \\ etienne.rapp@cnes.fr; valerie.pichetto@cnes.fr; christian.elisabelar@cnes.fr; denis.bausch@cnes.fr
}

(2) European Space Agency (ESA), Keplerlaan 1, 2201 AZ Noordwijk, The Netherlands

carsten.baur@esa.int

\begin{abstract}
In order to make accurate measurements, sun simulators used for solar cell characterisation need to be calibrated with standard solar cells. These so-called secondary working standards are derived from primary reference cells and are used for every cell measurement.

To generate primary reference cells, balloon calibration campaigns are a good compromise between accuracy, flight opportunity and cost.

CNES calibrates primary standards with stratospheric balloon flights since 1976. Safety rules limited the flight opportunities, so it was not possible to propose the calibration service since 2005 .

A new balloon facility is developed in CNES with the help of ESA in order to calibrate space solar cells with high accuracy. The first flight is planned in April 2017 in Alice Springs, Australia.
\end{abstract}

\section{INTRODUCTION}

The methods for AM0 calibration of solar cells fall into two broad categories; extraterrestrial and synthetic. Extraterrestrial methods attempt to measure the solar cell near the AM0 condition by measuring cells at high altitude (low air mass) or in space. Examples of this method include high altitude airplane, International Space Station and high altitude balloon. In the ideal case, these methods require no knowledge of the solar spectrum. High altitude balloons have long been recognized as the industry standard of extraterrestrial, AM0 solar cell calibration [1].

A recent study performed by ESA in collaboration with AZUR SPACE, Fraunhofer ISE and PTB (PhysikalischTechnische Bundesanstalt - German national metrological institute) demonstrated that both methods synthetic method used by PTB and CNES balloon were in perfect agreement within the measurement uncertainties claimed $(\leq 1 \%)$, at least for the top and the middle cell results. Only for the bottom cell there was a higher deviation in the order of $2.5 \%$ [2].

Synthetic methods rely on the knowledge of the AM0 spectrum. Ultimately, regardless of how much care is taken measuring the cell performance, the community is still reluctant to adopt the synthetic method as an alternative option that is fully equivalent to balloon or Lear Jet calibrations. Therefore, CNES, upon ESA request, decided to reinitiate a balloon calibration capability by developing a complete new payload to be launched on a new nacelle.

\section{HISTORY AND BACKGROUND}

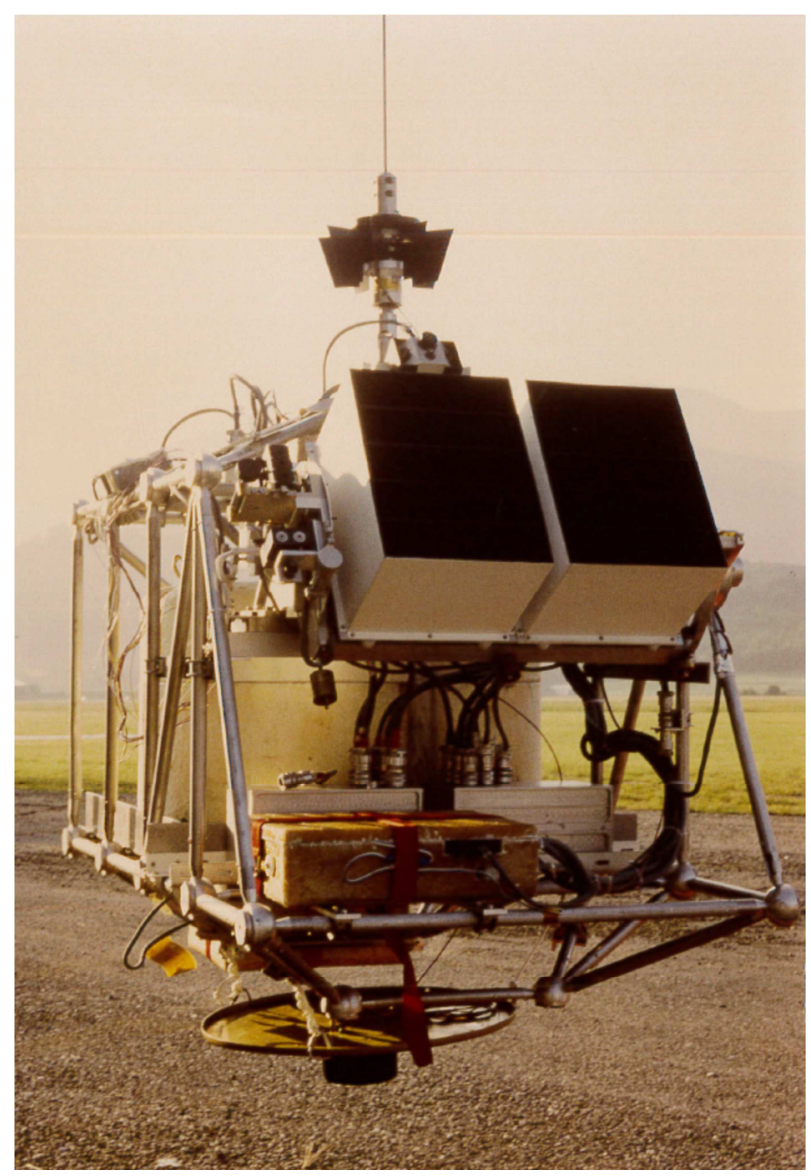

Figure 1: 1976-1996 flight configuration

The first flight occurred in 1976. The principles of the experiment were:

- Open stratospheric balloon $\left(100000 \mathrm{~m}^{3}\right.$, 
altitude between $34 \mathrm{~km}$ and $40 \mathrm{~km}$ )

- Dedicated sun-pointed nacelle $(110 \mathrm{~kg})$ under the balloon

- Sunshield (collimator, to avoid the parasitic light coming from the earth limbo and from the sun reflexion on the balloon envelope)

- Passive thermal control: the cells are cooled during the ascent then the temperature increases after sun pointing. The temperature is recorded continuously during the flight.

- Measurement of the open circuit voltage and near short circuit current: the voltmeter is switched from open circuit to a calibrated resistor (shunt) by means of electromechanical relays.

- Coefficients of correction: ks (sun-earth distance) and $\mathrm{kn}$ (residual atmosphere for low air mass $(0,005<\mathrm{AM}<0,014)$.

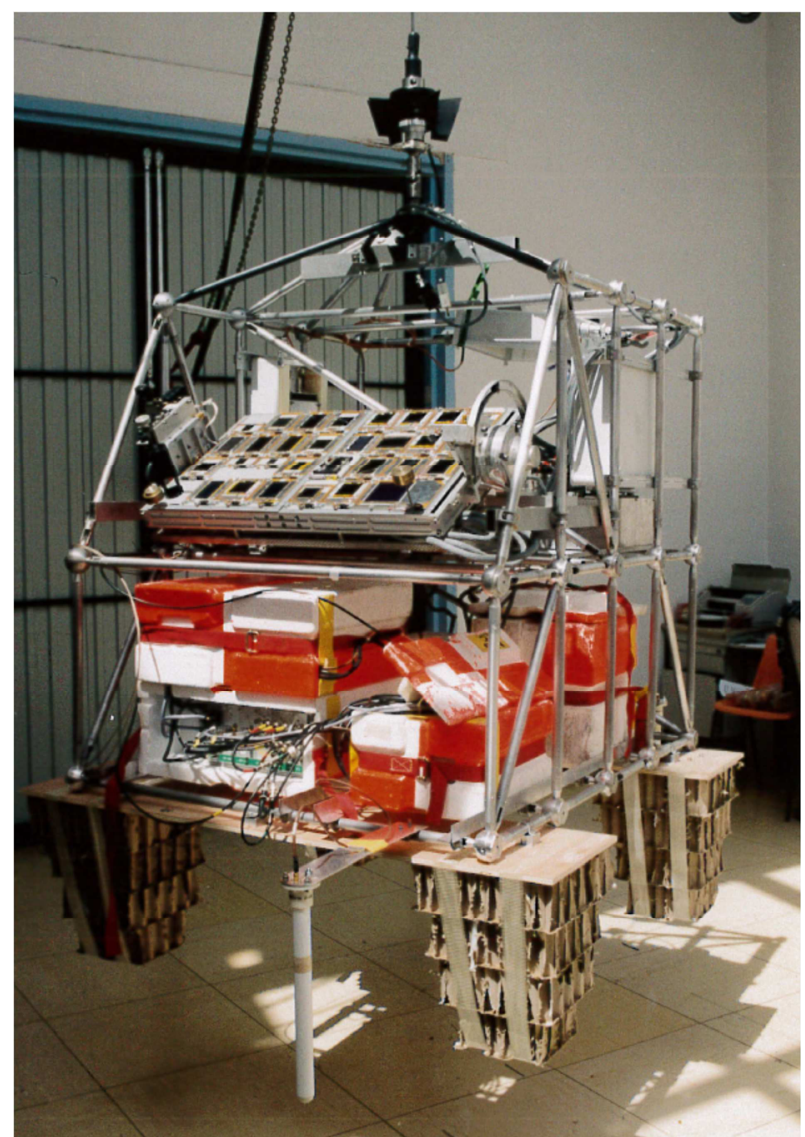

Figure 2: 1998-2001 flight configuration (collimator removed)

For the 1998 campaign, the nacelle is extended to carry more TTC (tracking, telemetry and control) and localisation equipment.

The measuring electronics is improved: it allows the calibration of 30 cells by performing measurements of the I-V characteristics from short circuit to open circuit at each temperature. The mass of the nacelle is now
$185 \mathrm{~kg}$. The analogic 2 -axes orientation system was used since the first flight.

In June 2001, some cells were degraded by the drop of the ballast (lead balls), so a second flight was planned in October. However, the nacelle was destroyed at landing.

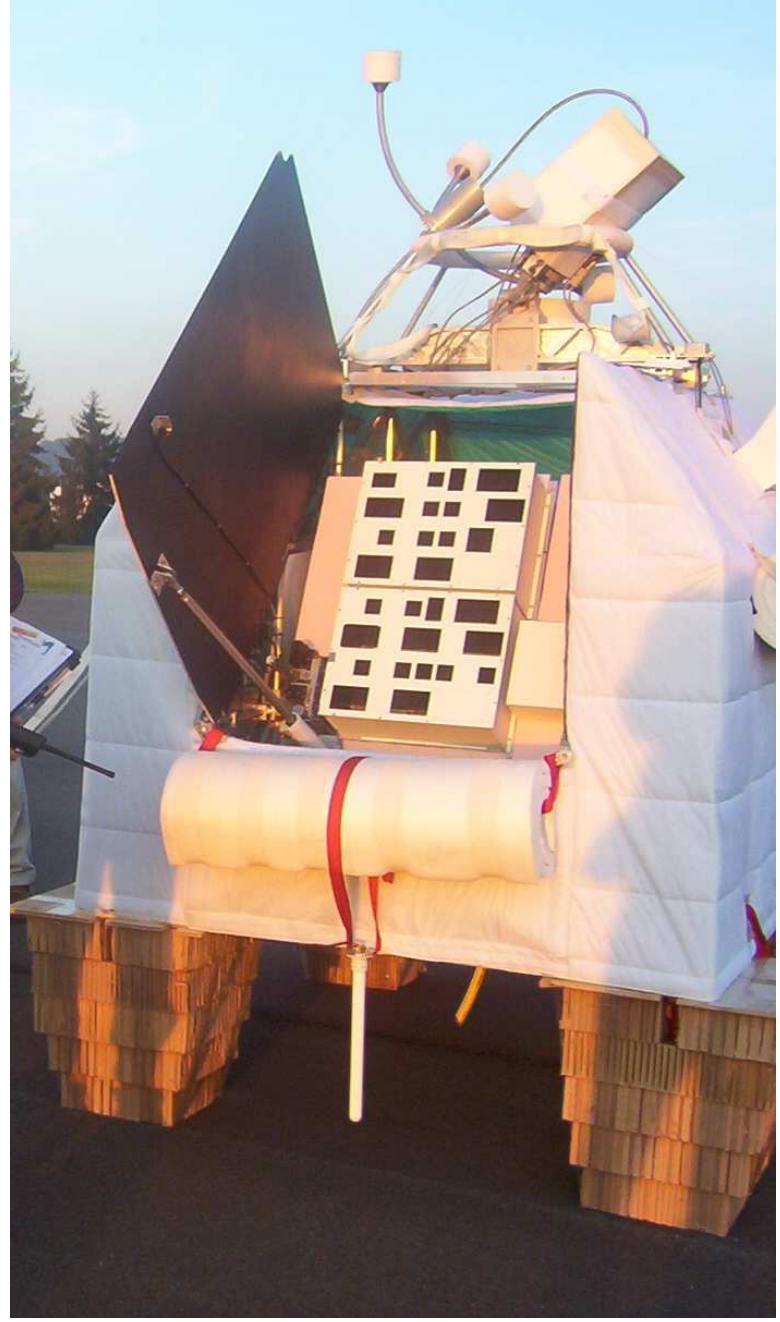

Figure 3: 2003-2005 configuration

In 2003, a multi-purpose pointed nacelle is used, with better performances. The total mass of the nacelle reaches $380 \mathrm{~kg}$.

After this flight, it was no more possible to fly in France.

In 2005, the balloon is launched from Teresina base in Brazil.

After 2005, no further campaign was organised due to either a lack of customer requests, i.e. not enough cells to calibrate, or the unavailability of the nacelle. The possibility to design a "mini-Casolba" nacelle, $50 \mathrm{~kg}$, able to fly 6 to 8 cells was also investigated. But flying a small nacelle is as difficult as a big one.

In 2014, ESA asked CNES to look at the possibility to restart the activity. A programme has been presented at the $17^{\text {th }}$ AM0 Workshop on Space Solar Cell Calibration in April 2014. It was received with enthusiasm by the 
community and CNES decided to start the project, with the help of ESA.

\section{BALLOON AND NACELLE}

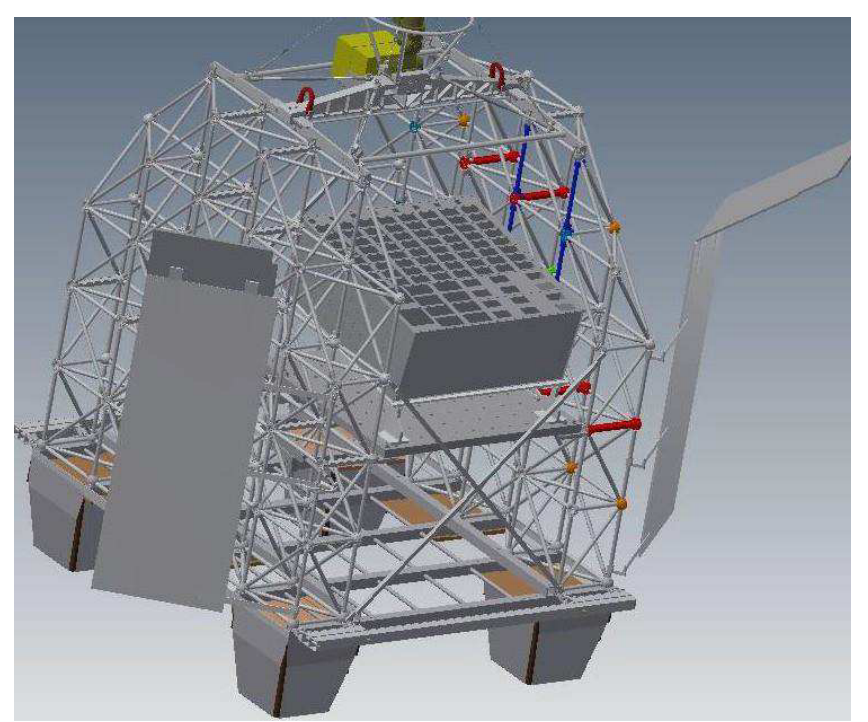

Figure 4: plate and collimator in the CARMEN nacelle

The CARMEN nacelle is a heavy multi-mission facility which provides all facilities: accurate pointing, energy, TM/TC (telemetry and telecommand) and data storage. The sun pointing accuracy is $1^{\circ}$ in azimuth and $0.5^{\circ}$ in elevation.

The maximum weight is $1100 \mathrm{~kg}$. Up to 4 scientific missions can fly simultaneously.

The open stratospheric balloon has a volume of $400000 \mathrm{~m}^{3}$ and allows a flight altitude of $36 \mathrm{~km}$ for a $750 \mathrm{~kg}$ load.

\section{MEASUREMENT SYSTEM}

The measurement system is based on CNES know-how, with a passive thermal control (the temperature of the cells decreases during the ascent and during non-pointed periods). The current-voltage curves (100 points from Voc to Isc - and 100 points from Isc to Voc) of the cells are measured continuously during the sun-pointed periods. The temperature of the cell is measured at the beginning and at the end of the I-V curve measurement. The temperature range is $\left[10^{\circ} \mathrm{C} ; 40^{\circ} \mathrm{C}\right]$ or more.

The measurement electronics is shared into 3 MCCS (Module de Calibration de Cellules Solaires) boxes. Each box is able to measure successively 32 solar cells. The electronics is able to measure the cell voltage up to $5.7 \mathrm{~V}$ and cell current up to $2.8 \mathrm{~A}$.

The measurement time is one second per cell. One measuring session consists of the measurement of the $\mathrm{I}-\mathrm{V}$ characteristics of all the cells and the complete measuring sequence comprises all the sessions of a sunpointed period. Up to 3 measuring sequences can be performed during the flight at different sun elevation or different altitudes in order to have a better view on the effect of residual atmosphere and to improve the accuracy of the corrections. In between the measuring sequences, the nacelle is pointed at $90^{\circ}$ of the sun direction and the cells are cooled down.

Cells are mounted on specific holders. The sun-oriented plate is able to support 63 mid-size holders (for cells up to $42 * 85 \mathrm{~mm}^{2}$ ), and 25 large-size holders (for cells up to $71 * 148 \mathrm{~mm}^{2}$ ). Double-size holders can be designed if needed. Each holder carries a temperature sensor (AD590M) and a protection by-pass diode. It is possible to mount NSCAP (NRL-NASA-AFRL Near Space Characterization of Advanced Photovoltaics) or also other type of cell holders on the plate by means of appropriate adaptors.

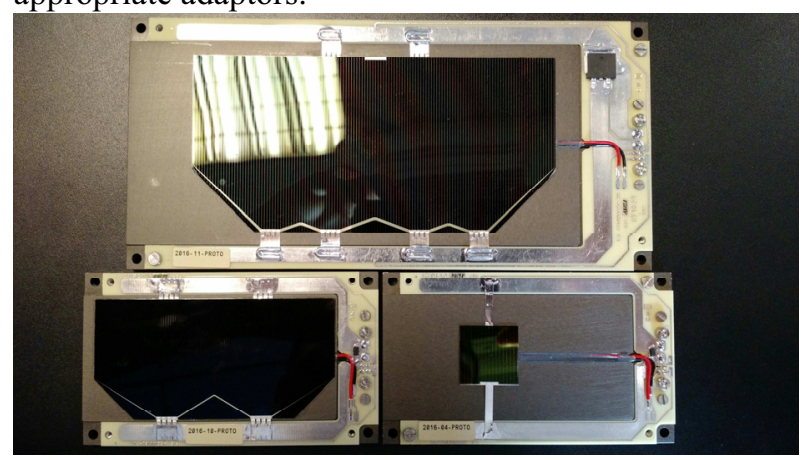

Figure 5: $12 * 6,8 * 4$ and $2 * 2 \mathrm{~cm}^{2}$ cells on holders

A collimator is placed in front of the plate in order to avoid any parasitic light and control the temperature range. The front mask of the collimator reproduces the shape of the cells and is redesigned for each flight.

All the flight data will be provided to the customers: rough current-voltage curves, temperature and current in the temperature sensor, but also corrections of the sunearth distance and atmospheric spectral absorption (air mass), altitude and localisation.

\section{UNCERTAINTY ANALYSIS}

The specification states that the uncertainties shall be lower than $1 \%$.

A list of the different uncertainties has been made from the previous flights: 8 of them are due to the environment, 6 come from the method used, 1 from the operator, 24 from the measuring instruments and finally 11 uncertainties come from the measurand.

Once every uncertainty was analysed we concluded that the main uncertainties come from the coefficient $\mathrm{kn}$, the MCCS and the temperature.

The temperature is measured with a probe. The datasheet states that the probe is accurate to less than $0.5^{\circ} \mathrm{C}$. Thus, it is possible to calculate the uncertainties 
related to the temperature and take this uncertainty into account for the calculation of the currents and kn. For more accurate verification, the measurement of the current in the probe will be provided.

The coefficient $\mathrm{kn}$ is defined as below:

$$
k n=\frac{\int R_{S}(\lambda) \cdot S_{A M 0}(\lambda) \cdot d \lambda}{\int R_{S}(\lambda) \cdot S_{A M X}(\lambda) \cdot d \lambda}
$$

So in order to calculate $\mathrm{kn}$, one needs the spectral response of the solar cells $\left(R_{S}\right)$, the solar spectrum at AM0 $\left(\mathrm{S}_{\mathrm{AM} 0}\right)$ and finally the solar spectrum at the altitude of the solar cells ( $\left.\mathrm{S}_{\mathrm{AMX}}\right)$.

In order to calculate the uncertainties related to $\mathrm{kn}$, we have to study the coefficient AM, the spectral responses and the solar spectrum. This leads to a Type B uncertainty. With the data from previous flight one finds the Type A uncertainty. Finally one obtains the following equations:

$$
\begin{gathered}
U_{c A}(k n)=3,4738 \cdot 10^{-4} \\
U_{c B}(k n)=1,1611 \cdot 10^{-4} \\
U_{c}(k n)=\sqrt{U_{c A}^{2}(k n)+U_{c B}^{2}(k n)}=3,6627 \cdot 10^{-4}
\end{gathered}
$$

Due to the components there is a difference between the empirical and theoretical voltages at the output of the analogic-digital converter. So, in order to correct this error a calibration is required. A first calibration was made but the range of the temperatures being wide; this calibration did not correct the voltages precisely. Indeed the components of the MCCS are sensitive to the temperature. Hence, different transfer functions are used depending on the temperature. The first one is used when the cells' temperatures are between -10 and $25^{\circ} \mathrm{C}$. The second transfer function is taken between $25^{\circ} \mathrm{C}$ and $40^{\circ} \mathrm{C}$. Finally, the last transfer function is used as soon as the temperature reaches $40^{\circ} \mathrm{C}$. The uncertainty will probably be reduced after the flight, taking into account the actual MCCS temperature range.

The idea of one transfer function, which depends of the temperature, was considered. However, once implemented, we saw that the errors did not decrease significantly.

The study performed on the MCCS gave the following uncertainties. They are expressed in ampere.

Range $2.8 \mathrm{~A}$

$$
U_{c}\left(I_{s c \_g r o s s}\right)=1,7953 \cdot 10^{-4} \cdot I_{s c \_g r o s s}+5,3258 \cdot 10^{-5}
$$

\section{$\underline{\text { Range } 250 \mathrm{~mA}}$}

$$
U_{c}\left(I_{s c_{-} \text {gross }}\right)=1,3008 \cdot 10^{-4} . I_{s c_{-} \text {gross }}+5,6639 \cdot 10^{-6}
$$

Using the following formula we can determine the uncertainty of the corrected current.

$$
\begin{aligned}
& U_{c}^{2}=\sum_{i=1}^{N}\left[\frac{\partial f}{\partial x_{i}}\right]^{2} \cdot u^{2}\left(x_{i}\right) \\
& I_{s c_{-} \text {corrected }}=I_{\text {sc_gross }} \cdot \mathrm{kn} . \mathrm{ks}
\end{aligned}
$$

The uncertainties of the corrected current of each cell will be calculated after the flight.

\section{REPRODUCIBILITY}

Three cells are measured frequently in order to check the reproducibility, during the period 1999-2005.

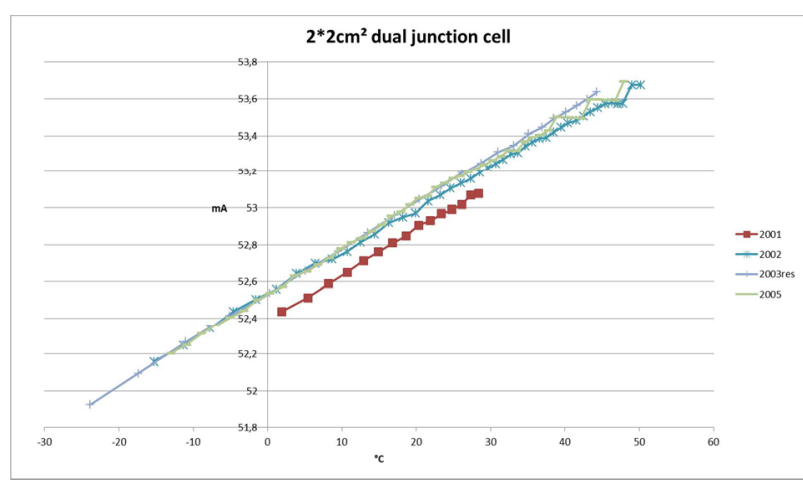

Figure 6:DJ cell reproducibility

For a dual-junction cell shown in Fig. 6, the maximum difference between measurements is $0.24 \%$ at $25^{\circ} \mathrm{C}$; the standard deviation is $0.14 \%$ (including a weighting factor equal to 1.7 for 4 samples).

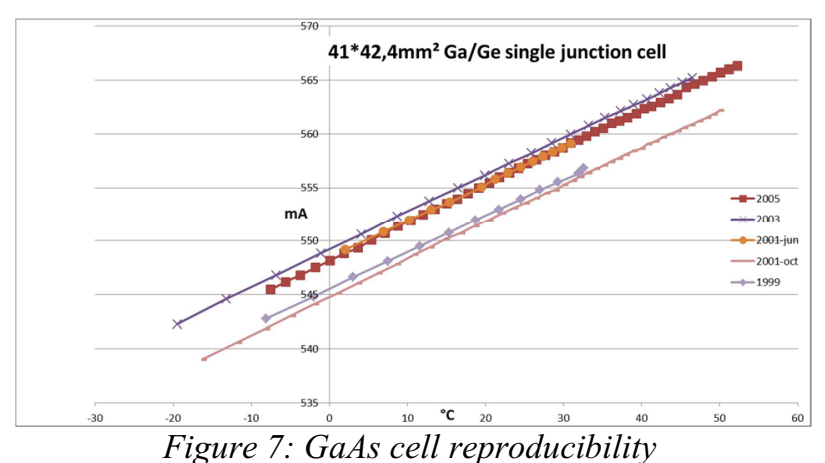

For GaAs single-junction cell shown in Fig. 7, the maximum difference between measurements is $0.64 \%$ at $25^{\circ} \mathrm{C}$; the standard deviation is $0.49 \%$ (including a weighting factor equal to 1.4 for 5 samples). 


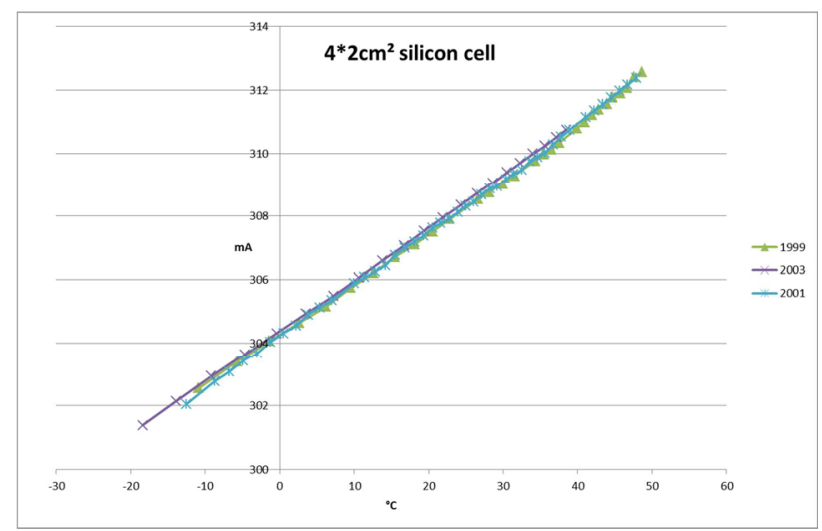

Figure 8: Silicon cell reproducibility

For the Silicon cell given in Fig. 8, the maximum difference between measurements is $0.06 \%$ at $25^{\circ} \mathrm{C}$; the standard deviation is $0.16 \%$ (including a weighting factor equal to 2.3 for 3 samples).

These cells will be re-calibrated during the next flight, using the new configuration and pieces of equipment.

\section{REFERENCES}

1. P. Jenkins, D. Wilt, D. Scheiman, B. Anspaugh, M. Pisczcor, D. Snyder, D. Ball, J. Juneau, H. Franco, D. Orr, S. Cannon, J. Lorentzen, R. Walters, M. Krasowski and B. Reed. A new air mass zero calibration facility using the high altitude Balloon method. In Proceedings of the 9th European Space Power Conference, St. Raphaël, France, 2011.

2. C. Baur, G. Siefer, R. Kern, S.Winter. Primary solar cell standards - comparison of extraterrestrial and synthetic calibration. In Proceedings of the 9th European Space Power Conference, St. Raphaël, France, 2011. 